\title{
Mechanical, Electrochemical, and Osteoblastic Properties of Gradient Tantalum Coatings on Ti6A14V Prepared by Plasma Alloying Technique
}

\author{
Meng Zhang ${ }^{1}$, Yong Ma ${ }^{1}{ }^{*}$, Jie Gao ${ }^{1}$, Hongjun Hei ${ }^{1}$, Wenru Jia ${ }^{1}$, Jin Bai ${ }^{1}$, Zhubo Liu ${ }^{2}$, Xiaobo Huang ${ }^{1}$, \\ Yanpeng Xue ${ }^{3, *}$, Shengwang $\mathrm{Yu}^{1}$ and Yucheng $\mathrm{Wu}^{1, *}$ \\ 1 Institute of New Carbon Materials, Taiyuan University of Technology, Taiyuan 030024, China; \\ cailiaoo@126.com (M.Z.); gaojie01@tyut.edu.cn (J.G.); heihongjun@tyut.edu.cn (H.H.); \\ jiawenru1017@163.com (W.J.); bai97541@163.com (J.B.); huangtyut@163.com (X.H.); \\ yushengwang@tyut.edu.cn (S.Y.) \\ 2 College of Mechanical and Vehicle Engineering, Taiyuan University of Technology, Taiyuan 030024, China; \\ liuzhubo@tyut.edu.cn \\ 3 National Center for Materials Service Safety, University of Science and Technology Beijing, \\ Beijing 100083, China \\ * Correspondence: mayongtyut@163.com (Y.M.); yanpengxue@ustb.edu.cn (Y.X.); wyc@tyut.edu.cn (Y.W.)
}

check for updates

Citation: Zhang, M.; Ma, Y.; Gao, J.; Hei, H.; Jia, W.; Bai, J.; Liu, Z.; Huang, X.; Xue, Y.; Yu, S.; et al. Mechanical, Electrochemical, and Osteoblastic Properties of Gradient Tantalum Coatings on Ti6Al4V Prepared by Plasma Alloying Technique. Coatings 2021, 11, 631. https://doi.org/ 10.3390/coatings 11060631

Academic Editor: Behnam Akhavan

Received: 11 May 2021

Accepted: 24 May 2021

Published: 25 May 2021

Publisher's Note: MDPI stays neutral with regard to jurisdictional claims in published maps and institutional affiliations.

Copyright: (c) 2021 by the authors. Licensee MDPI, Basel, Switzerland. This article is an open access article distributed under the terms and conditions of the Creative Commons Attribution (CC BY) license (https:/ / creativecommons.org/licenses/by/ $4.0 /)$.

\begin{abstract}
Plasma alloying technique capable of producing metallic coatings with metallurgical bonding has attracted much attention in dental and orthopedic fields. In this study, the effects of temperature and time of plasma tantalum (Ta) alloying technique on the mechanical, electrochemical, and osteoblastic properties of Ta coatings were systematically investigated. Ta coatings prepared at $800{ }^{\circ} \mathrm{C}$ possess better interfacial strengths than those prepared at 750 and $850{ }^{\circ} \mathrm{C}$, and the interfacial strength increases with prolonged alloying time (30-120 min). At $800{ }^{\circ} \mathrm{C}$, however, the increased proportion of the soft Ta deposition layer with alloying time in the whole coating impairs the surface mechanical properties of the entire coating, as convinced by decreased microhardness and wear resistance. Moreover, Ta coatings exhibit better corrosion resistance than the Ti6Al4V substrate in Dulbecco's modified Eagle medium. The enhanced adhesion and extracellular matrix mineralization level of osteoblasts demonstrate the better cytocompatibility and osteogenic activity of the Ta coating. Ta30 (Ta coating prepared at $800{ }^{\circ} \mathrm{C}$ for $30 \mathrm{~min}$ ) exhibits excellent mechanical, electrochemical, and osteoblastic behaviors and is promising in biomedical applications.
\end{abstract}

Keywords: tantalum; titanium alloy; interfacial strength; surface modification; biocompatibility

\section{Introduction}

Titanium (Ti) and its alloys have been widely used in dental and orthopedic fields due to their good mechanical properties, low weight ratio, and excellent biocompatibility [1-4]. However, the poor wear resistance of Ti alloys, which originated from their sensitivity to adhesive wear, remains a major concern for their practical applications [5,6]. Moreover, $\mathrm{Ti}$ alloys show better corrosion resistance due to the spontaneously formed stable oxide film on the surface. However, researchers remain cautious, since the passive film is only a few nanometers thick and can be easily eroded in chloride-containing human fluids $[7,8]$. Excessive metallic debris/ions, caused by wear and corrosion, may lead to inflammatory osteolysis [9,10]. Furthermore, additional elements used to develop versatile Ti alloys may not always be biosafe. Taking the most-used biomedical Ti6Al4V (TC4) as an example, the detrimental effects of aluminum (Al) and vanadium (V) ions on the central nervous system, digestive system, etc., have been reported by many researchers [11]. Fortunately, appropriate coatings prepared by surface modification not only can isolate the substrate from their service environment without compromising the bulk properties, but also can make up for the shortcomings of its predecessor. Therefore, it is a promising strategy 
to improve the wear resistance and corrosion resistance of titanium alloys by proper surface modification.

Tantalum (Ta) has been demonstrated to be a biocompatible metal with excellent corrosion resistance in many corrosive mediums, and the good biocompatibility of Ta implants has been proved by many studies [12-15]. Plasma spray [16], magnetron sputtering [15,17], and molten-salt electroplating [18] are commonly used to fabricate Ta coatings. However, the plasma-sprayed coatings have a porous and rough surface, making them more vulnerable to corrosive mediums. Furthermore, due to the lack of sufficient diffusion between the coating and substrate, the interfacial strength of coatings prepared by the above-mentioned methods still needs to be improved by an additional annealing treatment. Plasma alloying technique has been used to prepare biocompatibility and antibacterial coatings in recent decades [19-21]. During the alloying process, the interdiffusion of alloy elements at high temperature is responsible for the continuous and gradient distribution of elements from the deposition layer and substrate, which eventually results in a high interfacial strength of the coating. Usually, the hardness and wear resistance of surface-modified materials can also be improved due to the solid solution strengthening effect or the second phase strengthening effect [22-24]. Moreover, the high temperature required for the alloying treatment is generated by glow discharge. The heated region is confined to the sample surface with a gradient temperature from top to bottom. Thus, it is generally believed that the effect of plasma alloying technique on the mechanical properties of the substrate can be ignored [25].

In this study, a series of gradient Ta coatings were prepared on TC4 substrate by plasma alloying technique. The influence of alloying temperature $\left(750,800\right.$, and $\left.850^{\circ} \mathrm{C}\right)$ and time $(10,30,60$, and $120 \mathrm{~min})$ on surface morphology, the thickness of the deposition layer (DPL) and diffusion layer (DFL), and the interfacial strength of Ta coatings were systematically investigated. Furthermore, Ta coatings prepared at the optimized alloying temperature of $800{ }^{\circ} \mathrm{C}$ with superior interfacial strength were characterized in microhardness, wear resistance, corrosion resistance, and cytocompatibility. Ta coatings with high surface properties prepared by plasma alloying technique have potential applications in biomedical implants.

\section{Material and Methods}

\subsection{Sample Preparation}

TC4 plates with dimensions of $\Phi 12 \mathrm{~mm} \times 2 \mathrm{~mm}$ were used as substrates. Before surface treatment, they were mirror polished, and ultrasonically cleaned in acetone, ethanol, and deionized water in sequence. The plasma Ta alloying was conducted in a double-glow plasma alloying furnace. A pure Ta plate $(99.6 \%)$ with dimensions of $50 \mathrm{~mm} \times 50 \mathrm{~mm} \times 3 \mathrm{~mm}$ was used as the target (also the source electrode) to supply the Ta element. Prior to the Ta alloying process, samples were cleaned and pre-heated by argon (Ar) ion bombardment for $10 \mathrm{~min}$ at the target temperature. This process can also introduce many defects onto the sample surface to facilitate the formation of the Ta DFL. Ta atoms can be sputtered from the source electrode onto the specimen surface by glow discharge in Ar plasma in the alloying process. Subsequently, the nucleation and growth of the Ta coating occurs, and the interdiffusion between the Ta DPL and substrate happens due to their infinite solid solubility. In this study, Ta coatings were prepared at 750,800 , and $850{ }^{\circ} \mathrm{C}$ for 10, 30, 60 and $120 \mathrm{~min}$ at an Ar pressure of 40 Pa. The source electrode bias voltage was -500 to $-720 \mathrm{~V}$. The substrate bias voltage was -250 to $-470 \mathrm{~V}$. The voltage difference between the target electrode and substrate was kept at $250 \mathrm{~V}$. The distance between the Ta target and specimen surface was $18 \mathrm{~mm}$.

\subsection{Samples Characterization}

The surface and cross-sectional morphologies of the as-prepared coatings were observed by a field emission scanning electron microscopy (FE-SEM, GeminiSEM 300, Zeiss, Jena, Germany) equipped with an energy-dispersive X-ray spectrum detector (EDS, QX200, 
Bruker, Billerica, MA, USA). Variation of elements along the distance from the upper surface was analyzed by EDS mapping and line scan to determine the thickness of the DPL $\left(T_{\mathrm{DPL}}\right)$ and DFL $\left(T_{\mathrm{DFL}}\right)$. The phase compositions of the Ta coating were detected by an X-ray diffraction instrument (XRD, DX-2700, Haoyuan, Dandong, China). Average surface roughness was determined by a white-light interferometric profilometer (ContourGT-X3, Bruker, Karlsruhe, Germany). Static water contact angles of the Ta coatings were measured to evaluate their wettability. The microhardness of the Ta coating was measured by a micro-hardness tester (M-400-H1, LECO, St. Joseph, MI, USA) at a load of $500 \mathrm{~g}$ and a $15 \mathrm{~s}$ dwell time. All the samples were tested six times.

\subsection{Scratch Test}

The interfacial strengths of the Ta coating with substrate were determined by a scratch tester (Huijin Teer, Hangzhou, China). The load force was from 0 to $100 \mathrm{~N}$ at a rate of $60 \mathrm{~N} / \mathrm{min}$ for samples prepared at $750{ }^{\circ} \mathrm{C}$, and from 0 to $200 \mathrm{~N}$ at a rate of $120 \mathrm{~N} / \mathrm{min}$ for 800 and $850^{\circ} \mathrm{C}$ ones. The scratch morphologies were observed by SEM. The interfacial strengths were finally determined by acoustic emission signal and SEM images.

\subsection{Electrochemical Measurement}

An electrochemical station (PMC-2000, Princeton, NJ, USA) was used to test the corrosion resistance of Ta coatings by measuring the potentiodynamic polarization behavior in Dulbecco's modified Eagle medium (DMEM), which contains $10 \%$ fetal bovine serum and $1.5 \mathrm{~g} / \mathrm{L} \mathrm{NaHCO} 3$. The electrochemical test was performed using a conventional threeelectrode system with a saturated calomel electrode as the reference electrode, a platinum foil $(1 \mathrm{~cm} \times 1 \mathrm{~cm})$ as the counter electrode, and the samples as the working electrode. Potentiodynamic polarization curves were measured from $-1.6 \mathrm{~V}$ to $0.6 \mathrm{~V}$ (vs. $E_{\mathrm{OCP}}$ (open circuit potential)) at a scanning rate of $1 \mathrm{mV} / \mathrm{s}$ after being immersed in DMEM solution for $60 \mathrm{~min}$ to reach a stable $E_{\mathrm{OCP}}$.

\subsection{Wear Resistance}

An MFT-R4000 reciprocating friction apparatus (Huahui, Lanzhou, China) was used to test the wear resistance of the Ta-coated samples. At ambient temperature, these specimens were reciprocally rubbed with a $5 \mathrm{~mm} \mathrm{Si}_{3} \mathrm{~N}_{4}$ ball for 20 min under a load of $5 \mathrm{~N}$ at a frequency of $2 \mathrm{~Hz}$, and the reciprocating distance was $5 \mathrm{~mm}$. The morphologies of the worn surface were observed by FE-SEM to analyze the wear type and mechanism. The depth and width of the wear track were measured by a white-light interferometric profilometer (ContourGT-X3, Bruker, Karlsruhe, Germany) to calculate wear volume according to the study of Lin et al. [26].

\subsection{Cell Culture}

New-born mouse embryos derived from MC3T3-E1 subclone osteoblasts (Cell Bank of Chinese Academy of Sciences, Shanghai, China) were used to examine the biocompatibility and osteogenic activities of Ta coatings. The osteoblasts were cultured with an $\alpha$-MEM (Gibco, Thermo Fisher, New York, NY, USA) medium containing $10 \%$ fetal bovine serum, 100 units $/ \mathrm{mL}$ penicillin, and $100 \mu \mathrm{g} / \mathrm{mL}$ streptomycin with $5 \% \mathrm{CO}_{2}$ under a humidified atmosphere at $37^{\circ} \mathrm{C}$. The seeding density in each specimen was $4 \times 10^{4}$ cells per $\mathrm{cm}^{2}$ unless otherwise specified. Before inoculating, samples were sterilized in $75 \%$ ethanol for $30 \mathrm{~min}$, followed by being rinsed thrice with phosphate buffer solution (PBS). In osteogenic differentiation assays, $50 \mathrm{mg} / \mathrm{mL}$ ascorbic acid, $10 \mathrm{mM} \beta$-glycerophosphate, and $10 \mathrm{nM}$ dexamethasone were added to the complete medium to induce osteogenic differentiation.

\subsection{Cytotoxicity}

The LIVE/DEAD Cytotoxicity Kit for mammalian cells (Invitrogen, Thermo Fisher, Carlsbad, CA, USA) was adopted to evaluate the cytotoxicity of Ta coatings. The assay was conducted after culturing cells on Ta coatings for 3 days. Mirror polished TC4 was used as 
control. Under a fluorescence microscope (ECLIPSE Ts2R, Nikon, Tokyo, Japan), live cells were observed green and dead cells were stained red.

\subsection{Cell Adhesion}

The initial cell adhesion ability of osteoblasts on bare TC4 and Ta coatings was assayed by 4, 6-diamidino-2-phenylindole (DAPI, Beyotime) stain. The time point was set as $0.5,1$, and $4 \mathrm{~h}$. After incubation, $3 \%$ paraformaldehyde was used to fix cells. Then, the fixed cells were gently rinsed thrice with PBS, and stained with $50 \mu \mathrm{L}$ DAPI for $15 \mathrm{~min}$ in the dark. The stained cells were observed by a fluorescence microscope and had images taken from six random fields. Quantitative results were obtained by counting cell numbers of each field of each group.

\subsection{Cell Viability}

Cell Counting Kit-8 (CCK-8, Beyotime, Shanghai, China) was used to assay the osteoblastic viability cultured on Ta coatings for 1,3 , and 5 days. $\alpha$-MEM containing $10 \%$ CCK-8 solution was added into each well to incubate water-soluble formazan for $4 \mathrm{~h}$. The optical density was measured by a microplate reader (SpectraMax 384 Plus, Molecular Devices, San Jose, CA, USA) at $450 \mathrm{~nm}$.

\subsection{Cell Morphology}

Osteoblasts with a density of $2 \times 10^{4}$ cells per $\mathrm{cm}^{2}$ were seeded on the Ta coatings for $24 \mathrm{~h}$. After cultivation, all samples were gently rinsed thrice with PBS and then fixed with $2.5 \%$ glutaraldehyde for $40 \mathrm{~min}$, followed by dehydration using graded ethanol. The dehydrated samples were sprayed with a Au layer and observed by SEM.

\subsection{Extracellular Matrix Mineralization}

Osteoblasts cultured in a complete $\alpha$-MEM medium for 3 days were inducted to differentiation for 7 and 14 days, fixed in $75 \%$ ethanol for $60 \mathrm{~min}$, and stained with $40 \mathrm{mM}$ Alizarin Red S for $30 \mathrm{~min}$. The mineralized nodules were observed by a polarizing microscope (ECLIPSE LV100N POL, Nikon, Tokyo, Japan).

\subsection{Statistic Analysis}

All data were presented as means \pm standard deviations. PASW Statistics 18 software (IBM, Armonk, NY, USA) was utilized in statistical analysis. The significance level was obtained by one-way analysis of variance followed by the Student-Newman-Keuls test. The statistic difference was considered as significant when $p<0.05$. All the tests were conducted three times.

\section{Results and Discussion}

\subsection{Parameter Optimization of Plasma Ta Alloying Technique}

Figure 1 shows the surface morphology of Ta coatings prepared with different temperatures and time. Typical cellular grains can be observed in groups with lower alloying temperatures (at $750{ }^{\circ} \mathrm{C}$ for $10,30,60$, and $120 \mathrm{~min}$ ) and shorter time (at 750, 800, and $850{ }^{\circ} \mathrm{C}$ for $10 \mathrm{~min}$ ). (The abnormal grain size of the Ta coating prepared at $750{ }^{\circ} \mathrm{C}$ for $120 \mathrm{~min}$ will be discussed in the interfacial strength section). With the extension of alloying time (30-120 $\mathrm{min}$ ) at 800 and $850{ }^{\circ} \mathrm{C}$, the pronounced reverse-sputtering effect leads to the appearance of ridge-shape structures on the Ta coatings' surfaces. With the increase in alloying temperature and time, the Ta coatings' grain size and surface roughness increases, and the compactness decreases. The reverse-sputtering effect at $750{ }^{\circ} \mathrm{C}$ on surface morphology can be ignored, as evidenced by the cellular shape of Ta grains compared to those ridge-shape structures at 800 and $850{ }^{\circ} \mathrm{C}$. In the plasma alloying process, the reverse-sputtering effect refers to the detachment and return of alloying atoms from the cathode (workpiece) surface to the environment or even to the source electrode surface [24]. As previously reported, higher voltages of both the anode and cathode can lead to a higher 
alloying temperature and intensified reverse-sputtering effect, accelerated deposition and diffusion rates, and eventually the remolded surface morphology [22,24].

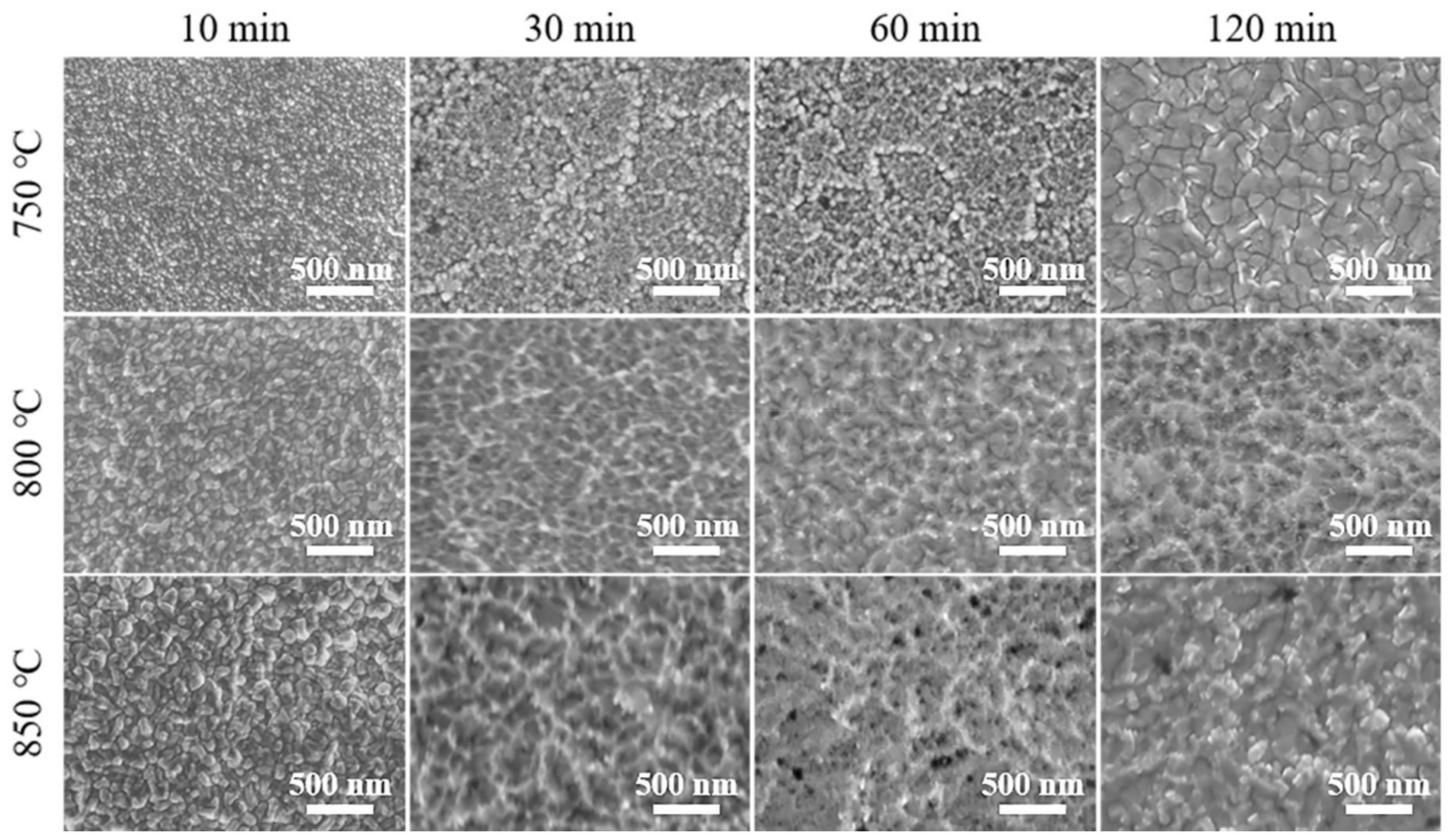

Figure 1. SEM images of Ta coatings prepared at 750,800 , and $850{ }^{\circ} \mathrm{C}$ for $10,30,60$, and $120 \mathrm{~min}$.

A representative cross-sectional image of the Ta coating $\left(800{ }^{\circ} \mathrm{C}, 30 \mathrm{~min}\right)$ is depicted in Figure 2a. A compact and homogeneous Ta coating without cracks is observed on TC4 substrate. An EDS line scan was performed to reveal the variation tendency of elements content. According to Figure $2 \mathrm{~b}$, the Ta alloyed sample can be roughly divided into the DPL (I), DFL (II), and substrate (III) from outside to inside. The DPL and DFL together constitute the coating. The thickness of the DPL ( $\left.T_{\mathrm{DPL}}\right)$ of the Ta coating prepared at $800{ }^{\circ} \mathrm{C}$ for $30 \mathrm{~min}$ is $\sim 1.7 \mu \mathrm{m}$. The DFL is a transitional region with a gradient Ta content, and the thickness of the DFL ( $T_{\mathrm{DFL}}$ ) is up to $\sim 1 \mu \mathrm{m}$ thick. It is worthy to note that $\mathrm{Al}$ exhibits uphill diffusion behavior different from the $\mathrm{V}$ element in the Ta coating, which was also found in coatings with other fabrication parameters (not shown). The uphill diffusion of $\mathrm{Al}$ may be explained by the higher affinity of $\mathrm{Al}$ with Ta than that of Ti. The gradient distribution of alloying elements in the coating not only improves the interfacial strength between the coating and substrate, but also exerts solid solution strengthening and/or second phase strengthening effects.

The statistic results of variation of $\mathrm{T}_{D P L}$ and $\mathrm{T}_{D F L}$ with alloying temperatures and time are exhibited in Figure 2c. At the same alloying temperature, the $T_{\mathrm{DPL}}$ and $T_{\mathrm{DFL}}$ of Ta coatings all increase with the extension of alloying time. Similar results can be found in Ta coatings with the same alloying time. Figure $2 \mathrm{~d}$ intuitively plots the variation of $T_{\mathrm{DFL}} /\left(T_{\mathrm{DPL}}+T_{\mathrm{DFL}}\right)$, which decreases with the alloying temperature and time. This decline tendency could be explained by different growth mechanisms of the DPL and DFL. The growth of the DPL is controlled by the spurting of particles of alloying elements from the source electrode, and the subsequent adsorption, nucleation, and growth of these particles on the substrate surface. The $\mathrm{T}_{D P L}$ increases linearly with alloying time. In contrast, the diffusion process is dominated by the chemical potential difference of elements between the coating and substrate. Meanwhile, many defects pre-introduced into the substrate surface also contribute to the interdiffusion [27]. Generally, the $T_{\mathrm{DFL}}$ increases parabolically with alloying time. Hence, the deposition rate is always much faster than the diffusion rate. 

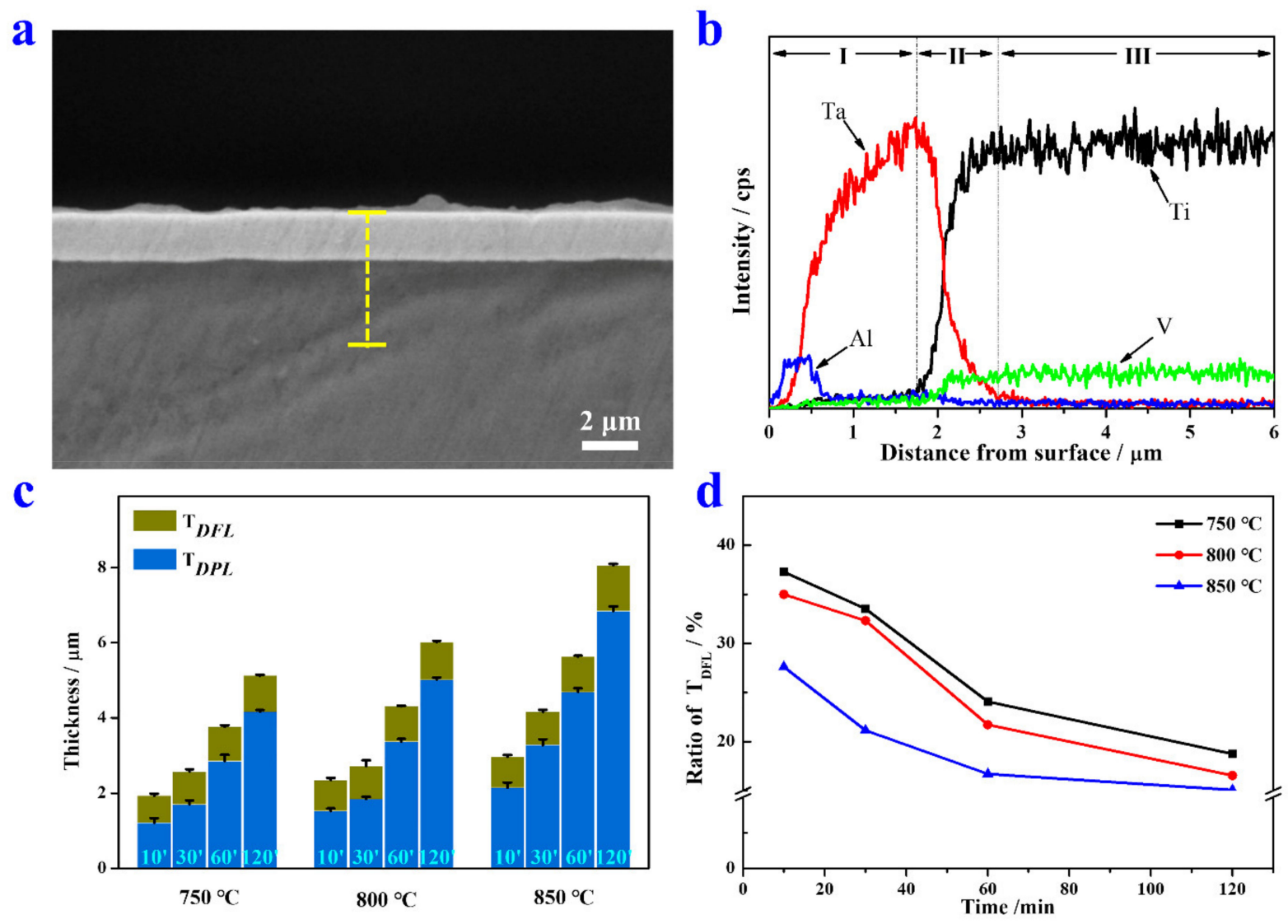

Figure 2. (a) Cross-sectional SEM image of the Ta coating prepared at $800{ }^{\circ} \mathrm{C}$ for $30 \mathrm{~min}$. (b) A corresponding EDS line scan of the yellow dotted line in (a). (c) The thickness of the deposition layer and diffusion layer prepared at 750,800 , and $850{ }^{\circ} \mathrm{C}$ for 10, 30, 60, and $120 \mathrm{~min}$. (d) Variation of $T_{\mathrm{DFL}}$ ratio with alloying time and temperature.

The interfacial strengths of the Ta coating are determined by the critical loads when delamination becomes dominant on the trackside [28]. As summarized in Figure 3, both higher $\left(850^{\circ} \mathrm{C}\right)$ or lower $\left(750^{\circ} \mathrm{C}\right)$ alloying temperatures lead to poor interfacial strength, and the alloying temperature for optimal interfacial strength of the Ta coating is $800^{\circ} \mathrm{C}$. The interfacial strengths of Ta coatings prepared at 800 and $850{ }^{\circ} \mathrm{C}$ increase continuously with alloying time, while those at $750{ }^{\circ} \mathrm{C}$ increase first and then decrease at $120 \mathrm{~min}$. Irrespective of the alloying temperature, coatings prepared with a shorter alloying time (10 $\mathrm{min}$ ) are too thin and can be easily punctured when contacting with the slipper. The Ta coating prepared at $750{ }^{\circ} \mathrm{C}$ for $120 \mathrm{~min}$ was peeled from the substrate, which may be the main reason for the abnormal grain growth (Figure 1). Even though no areas were being peeled continuously with load increase, such a coating is difficult for engineering applications. The corresponding scratch morphology and acoustic emission signal of Ta coatings are depicted in Figure S1 (Supplementary Materials). The empirical formula proposed by Hogmark et al. [29] shows that the minimum critical loading of coatings for engineering use should not be less than $30 \mathrm{~N}$ when using Rockwell diamond indenter scratches. Except for coatings prepared for $10 \mathrm{~min}$ at different alloying temperatures, other Ta coatings' interfacial strengths are roughly greater than $50 \mathrm{~N}$, which fully meets the practical requirement. The high interfacial strength of plasma alloyed coatings is attributed to the gradient strengthening layer [30]. Higher alloying temperature $\left(\geq 850^{\circ} \mathrm{C}\right)$ will generally cause coating peeling due to the difference of thermal expansion coefficient between the substrate and coating [31]. In comparison, a lower alloying temperature $\left(\leq 750{ }^{\circ} \mathrm{C}\right)$ leads to reduced density and energy levels of alloying particles; thus, reducing the mechanical locking effect on interfacial strength [30]. 


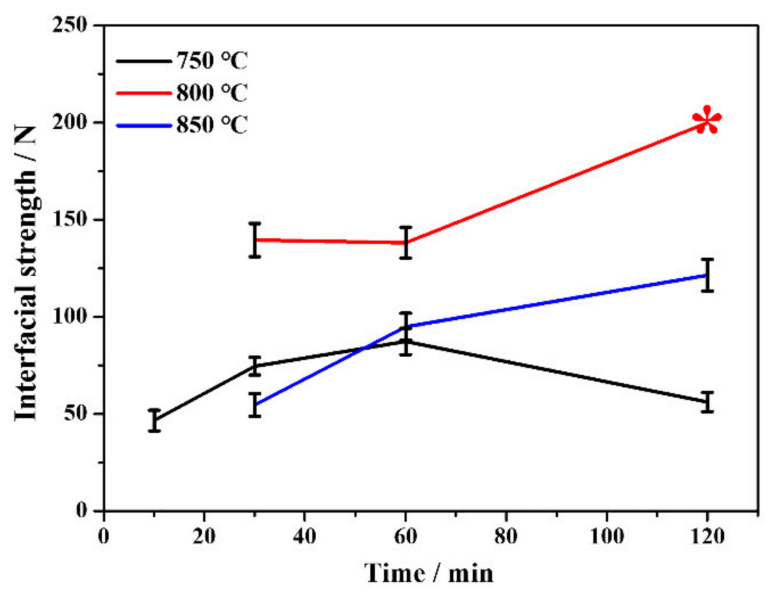

Figure 3. Variation of interfacial strength of Ta coatings with alloying temperatures and time. The asterisk represents the estimated value.

In summary, alloying temperature and time have significant effects on the morphology, deposition and diffusion speed, and interfacial strength of the coatings. Ta coatings prepared at $800{ }^{\circ} \mathrm{C}$ exhibit regular micromorphology with higher interfacial strength than those prepared at 750 and $850^{\circ} \mathrm{C}$. The alloying time can also be extended to prepare thicker coatings at $800{ }^{\circ} \mathrm{C}$ with enough interfacial strengths (compared with $750{ }^{\circ} \mathrm{C}$ ). Therefore, Ta coatings prepared at $800^{\circ} \mathrm{C}$ with different alloying time (30,60 and $120 \mathrm{~min}$ ) were chosen for further characterization and performance tests in the follow-up work, and they were denoted as Ta30, Ta60, and Ta120, respectively.

\subsection{Characterization of Ta Coating}

XRD patterns of Ta coatings prepared at $800{ }^{\circ} \mathrm{C}$ are depicted in Figure 4a. Except for the diffraction peaks of hexagonal $\alpha$-Ti and cubic $\beta$-Ti in TC4 substrate, peaks at $2 \theta$ angles of $38.2^{\circ}, 39.2^{\circ}$ and $40.2^{\circ}$ corresponding to tetragonal $\beta$-phase Ta (PDF \#25-1280); and peaks at $2 \theta$ angles of $38.5^{\circ}$ and $69.6^{\circ}$ corresponding to cubic $\alpha$-phase Ta (PDF \#04-0788) were also detected, confirming that Ta coatings were fabricated on the TC4 substrate. Peaks of tetragonal $\mathrm{Al}_{3} \mathrm{Ta}\left(32.9^{\circ}\right.$ and $59.2^{\circ}$, PDF \#02-1128) appearing in Ta30 further corroborate that the $\mathrm{Al}$ element diffuses outwards from the TC4 substrate and forms a compound with the Ta element. Interestingly, Ta exists in a tetragonal crystalline form in Ta30 and transforms into a cubic crystalline form when the alloying time exceeds $60 \mathrm{~min}$. The crystalline transformation of the Ta coating with alloying time could be explained by the sensitivity of $\beta$-Ta to impurity gas. Tetragonal $\beta$-Ta is an impurity stable phase capable of dissolving massive impurity atoms such as $\mathrm{O}$ and $\mathrm{N}$ [32]. Although high purity argon was used in this study, the ultimate vacuum of the alloying cavity is still limited. The impurity gas will interact with the coating at the initial period of the alloying process, and the impurity gas will be consumed and diluted within the coating with the extension of alloying time [33]. Hence, the phase transformation of Ta from $\beta$ to $\alpha$ occurs with the prolongation of alloying time. Figure $4 \mathrm{~b}$ shows the static water contact angle of Ta coatings prepared at $800{ }^{\circ} \mathrm{C}$. There are no significant differences between bare TC4 $\left(49.9^{\circ} \pm 4^{\circ}\right)$, Ta30 $\left(46.8^{\circ} \pm 5.2^{\circ}\right), \operatorname{Ta} 60\left(42.5^{\circ} \pm 4.6^{\circ}\right)$, and Ta120 $\left(49.3^{\circ} \pm 4^{\circ}\right)$. These results demonstrate that the hydrophilia of Ta coatings are roughly comparable to that of mp TC4. With the increase in alloying time, the surface roughness of Ta coatings increases continuously, as shown in Figure 4c. The Ta30 group shows the minimum value $(230 \pm 26.5 \mathrm{~nm})$, and the Ta120 group has the maximum one $\left(542.5^{\circ} \pm 66.5 \mathrm{~nm}\right)$. The increase in Ta coatings' surface roughness with alloying time may be explained by the grain growth and a growing number of defects caused by the reverse-sputtering effect [24]. As shown in Figure 4d, Vicker's hardness of Ta coatings prepared at $800^{\circ} \mathrm{C}$ is significantly improved than that of TC4 substrate. Ta30 has a maximum hardness of $540.6 \pm 13.8$ HV0.5. The hardness of Ta coatings decreases slightly with alloying time. By comparing with Figure $2 d$, the hardness of the Ta coating is 
positively correlated with the ratio of $T_{\mathrm{DFL}} /\left(T_{\mathrm{DPL}}+T_{\mathrm{DFL}}\right)$. The DPL is mainly composed of pure Ta with lower hardness than the TC4 substrate [34], which weakens the hardness of the overall coating; the DFL is a solid solution strengthened region, and the Ta element incorporating into TC4 increases the resistance of dislocation movement; thus, leading to an increased hardness of the coating [35]. Moreover, newly formed $\mathrm{Al}_{3} \mathrm{Ta}$ may also have a finite strengthening effect on Ta coatings. In addition, the second phase strengthening effect could be impaired with alloying time extension due to the limited diffusion of $\mathrm{Al}$ (especially after $60 \mathrm{~min}$, as confirmed by the disappearance of $\mathrm{Al}_{3} \mathrm{Ta}$ in Figure 4a). Overall, the rapidly increasing percentage of $T_{\mathrm{DPL}}$ is the main reason for the hardness decrease in Ta coatings with alloying time. Implants with sufficient hardness can weaken, or even eliminate, external damages such as scratch and wear, which is beneficial for prolonging the implant's service life.
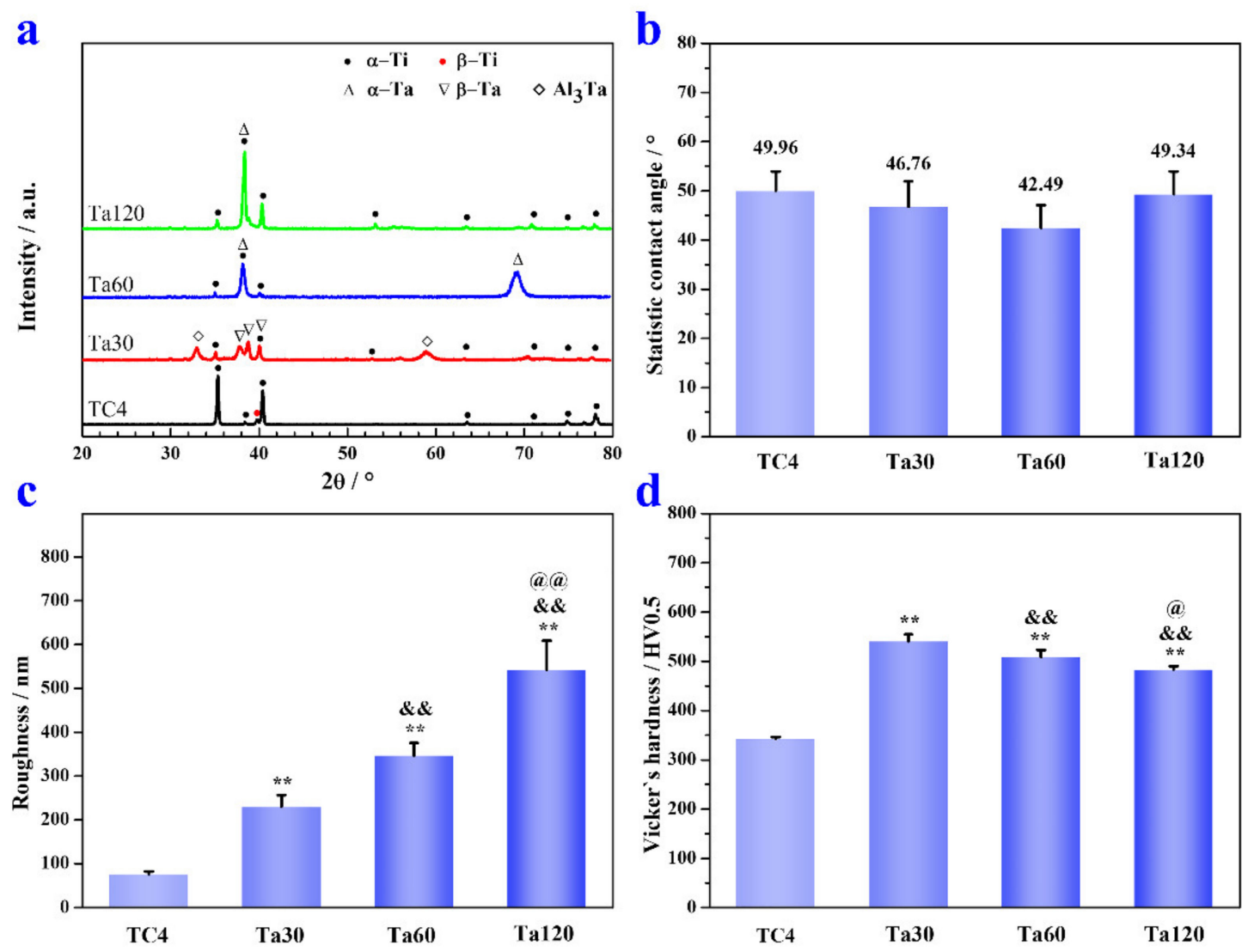

Figure 4. The XRD pattern (a), static water contact angle (b), average surface roughness (c) and Vicker's hardness (d) of Ta coatings prepared at $800{ }^{\circ} \mathrm{C}$ for 30,60 and $120 \mathrm{~min} .{ }^{*} p<0.05$ and ${ }^{* *} p<0.01$, compared to TC4, ${ }^{\&} p<0.05$ and ${ }^{\& \&} p<0.01$ compared to Ta30, ${ }^{@} p<0.05$ and ${ }^{\circledR @} p<0.01$ compared to Ta60.

\subsection{Wear Resistance}

The wear scare profiles and SEM images of the Ta coating and TC4 substrate are shown in Figure 5a,b, respectively. The wear width, depth, and wear volume are listed in Table 1. The TC4 substrate has the largest wear width and the minimum wear depth among all groups. The wear width and depth of Ta coatings all increase with the extension of alloying time. Ta coatings prepared with shorter alloying time possess a lower wear volume. Ta30 shows the best wear resistance than other groups, and Ta60 shares a closer wear volume level than the TC4 substrate. Ta120 reaches the worst wear resistance of Ta coatings in this study. Figure 5b displays the wear morphologies of the TC4 substrate and Ta coatings. Severe adhesive wear and abrasive wear can be observed on the TC4 surface, which is confirmed by large pieces of wear debris re-cold welded to the wear scare. 
The wear morphology of Ta30 is the smoothest among all the Ta coating groups, and the wear debris is smaller in size with less amount. The size and debris amount increases, and the ground surfaces become coarser gradually from Ta30 to Ta120. The wear behavior of Ta coatings with different thicknesses is a combination of adhesive wear and abrasive wear. However, the adhesive wear increases with the thickening of the Ta coating. The wear resistance of metallic materials is strongly influenced by their hardness and surface roughness [36-38]. Although the hardness of Ta coatings is much higher than that of the TC4 substrate, high friction is caused by the increase in roughness along with the coating thickening, eventually aggravating the wear performance of the Ta coating.

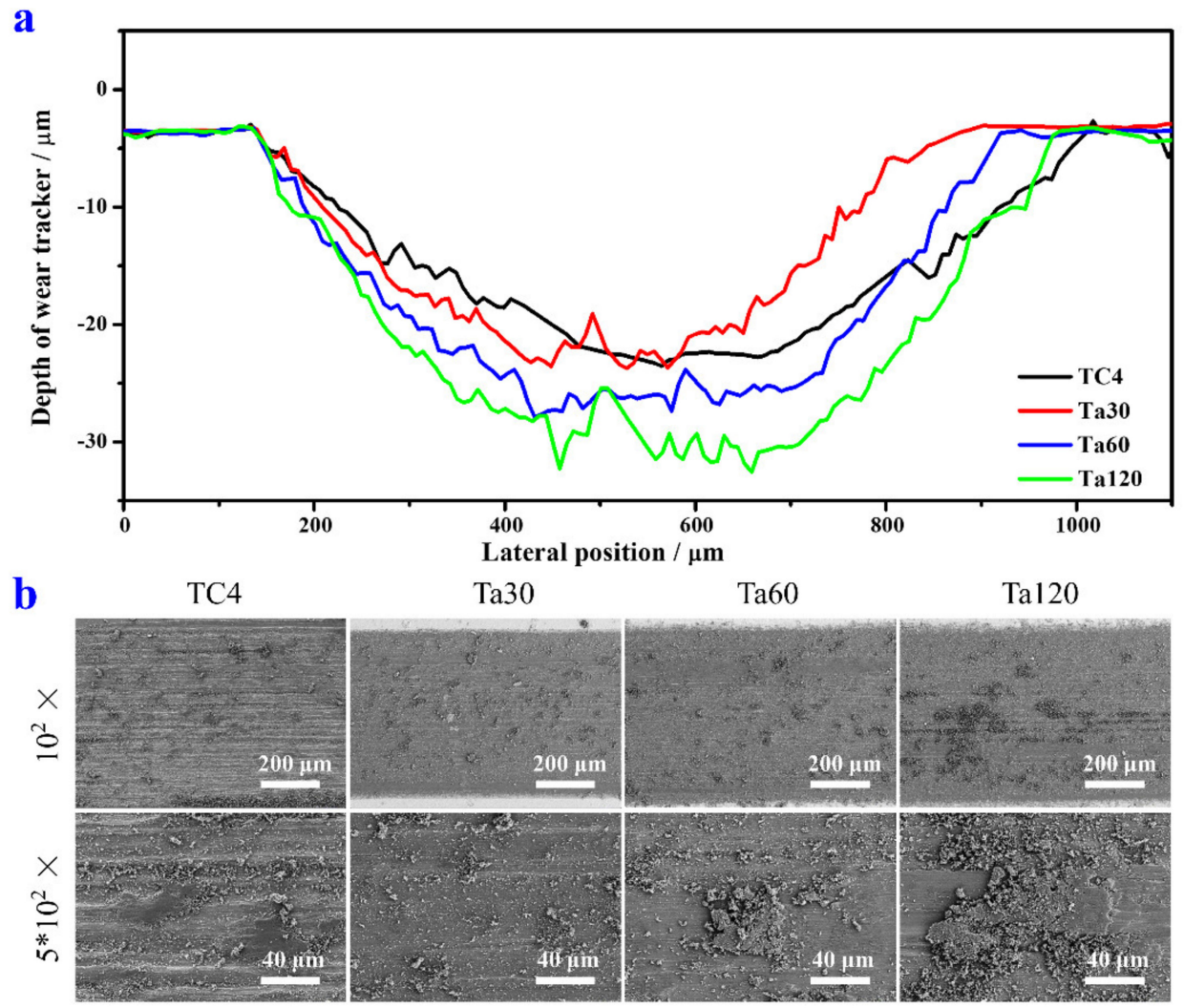

Figure 5. The wear scars' profile curves (a) and the corresponding SEM image morphologies (b) of TC4 and Ta coatings prepared at $800{ }^{\circ} \mathrm{C}$ with different alloying time.

Table 1. Wear width, depth, and volume of Ta coatings after grinding against $\mathrm{Si}_{3} \mathrm{~N}_{4}$ balls with a load of $5 \mathrm{~N}$ for $20 \mathrm{~min}$.

\begin{tabular}{|c|c|c|c|}
\hline Sample & $\begin{array}{c}\text { Wear Width } \\
\text { b/mm }\end{array}$ & $\begin{array}{l}\text { Wear Depth } \\
h / 10^{-3} \mathrm{~mm}\end{array}$ & $\begin{array}{l}\text { Wear Volume } \\
W v / 10^{-3} \mathrm{~mm}^{3}\end{array}$ \\
\hline TC4 & 0.88 & 19.87 & 58.66 \\
\hline Та30 & 0.73 & 20.54 & 50.24 \\
\hline Ta60 & 0.77 & 22.72 & 58.45 \\
\hline Ta120 & 0.82 & 28.55 & 80.68 \\
\hline
\end{tabular}

\subsection{Corrosion Behavior}

The potentiodynamic polarization curves and detailed electrochemical parameters of bare TC4 and Ta coatings are displayed in Figure 6 and Table 2, respectively. The more noble $E_{\text {corr }}$ values of Ta coatings indicate their better thermodynamic stability and low corrosion tendency than the bare TC4. In addition, there is little difference in $E_{\mathrm{corr}}$ between the Ta coating groups. The lower $I_{\text {corr }}$ of Ta coatings than that of the TC4 substrate also implies their higher corrosion resistance. By comparison, Ta30 and Ta60 possess close $I_{\text {corr }}$ 
$\left(2.63 \times 10^{-2}\right.$, and $2.05 \times 10^{-2} \mu \mathrm{A} \mathrm{cm}{ }^{-2}$, respectively), while the $I_{\text {corr }}$ of Ta120 shows a slight increase. The chemical property and surface status of the coating can influence the corrosion resistance of materials. Many researchers have reported the corrosion resistance of Ta. The high chemical stability of the passive oxide on the surface contributes to the excellent corrosion resistance of Ta coatings [15]. Moreover, although the thickness of the Ta coating increases with the prolonging of alloying time, the compactness of the Ta coating decreases gradually, evidenced by the SEM images and surface roughness results. The looser holes on the coating act as channels for corrosive media to enter and accelerate corrosion, and lead to decreased $E_{\text {corr }}$ and increased $I_{\text {corr }}$ than the compact coatings.

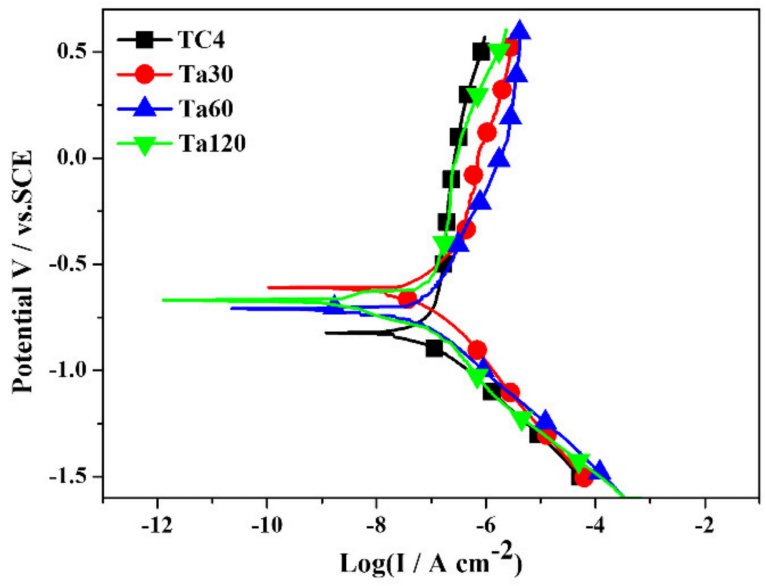

Figure 6. The Potentiodynamic polarization curves of Ta coatings in DMEM at $37^{\circ} \mathrm{C}$. Mirror polished TC4 was used as control.

Table 2. Electrochemical parameters of Ta coatings with different alloying time. The tests were conducted in a DMEM solution at $37^{\circ} \mathrm{C}$.

\begin{tabular}{cccc}
\hline Sample & $\boldsymbol{E}_{\text {corr }} / \mathbf{m V}$ & $\boldsymbol{I}_{\text {corr }} /\left(\boldsymbol{\mu} \mathbf{A ~ \mathbf { ~ m } ^ { - 2 } )}\right.$ & $\boldsymbol{\beta}_{\mathrm{c}} /\left(\mathbf{m v} \mathbf{d e c a d e}^{-\mathbf{1})}\right.$ \\
\hline TC4 & -1.08 & $1.06 \times 10^{-1}$ & 210.72 \\
Ta30 & -0.62 & $2.63 \times 10^{-2}$ & 168.12 \\
Ta60 & -0.71 & $2.05 \times 10^{-2}$ & 147.21 \\
Ta120 & -0.67 & $7.54 \times 10^{-2}$ & 204.46 \\
\hline
\end{tabular}

\subsection{Cell Behavior}

Osteoblasts were used as in vitro models to evaluate the cytocompatibility of TC4 and Ta coatings. Figure $7 \mathrm{a}, \mathrm{c}$ present the cytotoxicity and proliferation activity of osteoblasts. Figure $7 \mathrm{~b}, \mathrm{~d}$ are the qualitative and quantitative results of initial osteoblastic adhesion, respectively. The LIVE/DEAD assay, conducted for 3 days, in Figure 7a indicates that Ta coatings possess no cell toxicity. Proliferation activity results in Figure 7c show no significant difference between the substrate and Ta coatings at the same interval, demonstrating the well osteoblasts viability on Ta coatings. Ti, Ta and their alloys have been reported to be biocompatibility materials and have been clinically used in dental and bone replacement applications [3,12]. Fluorescent images of osteoblasts after culturing for $4 \mathrm{~h}$ are depicted in Figure $7 \mathrm{~b}$, and the cell nuclei are stained blue. Cells are distributed evenly on all sample surfaces. Cellular densities on Ta coatings are higher than the control group and increase with surface roughness. The quantitative results of cell adhesion are presented in Figure $7 \mathrm{~d}$. After $0.5 \mathrm{~h}$, the number of cells adhered to Ta coatings is roughly equal (Ta60) or lower (Ta30 and Ta120) than that of the control. After $1 \mathrm{~h}$, the cell number on Ta30 is higher than that on the control group, while the other groups are at the same level as the control. After $4 \mathrm{~h}$, the adhesion capacity of osteoblasts in each group is consistent with that in Figure 7b. Ta coatings show a higher cell adhesion ability than the TC4 substrate and it 
is pronounced with surface roughness. It has been demonstrated that surface roughness influences the synthesis of focal adhesion protein and the interfacial stress when cells contact with the surrounding extracellular matrix $[39,40]$. Results here indicate that cell adhesion ability is improved within the surface-roughness scope of our study $(<0.6 \mu \mathrm{m}$ or so).

a

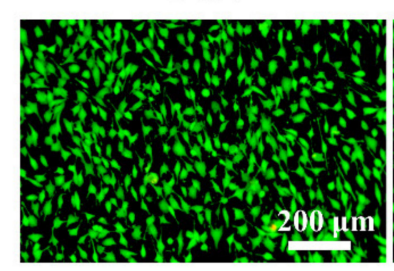

b

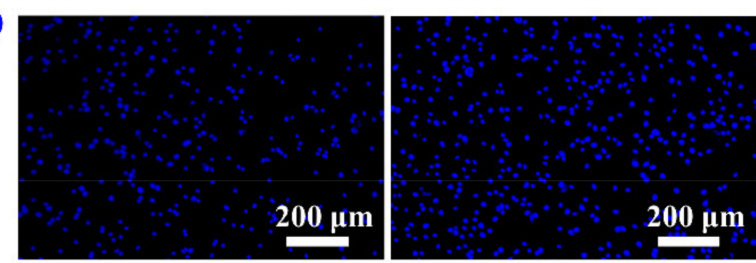

c

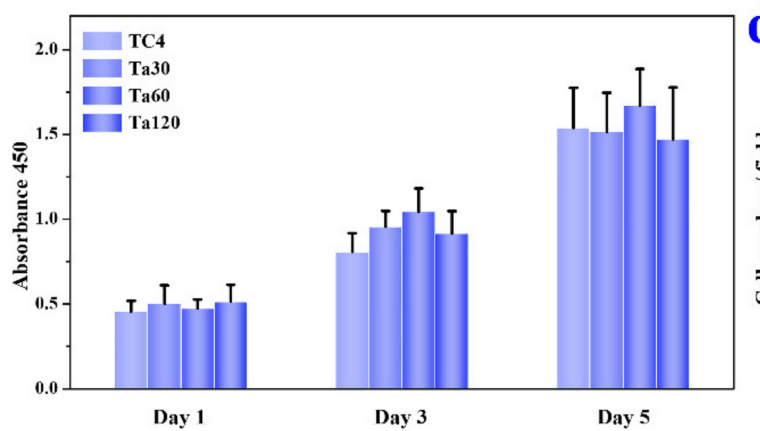

Ta30

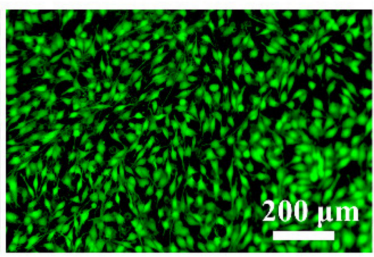

Day 3
Ta60
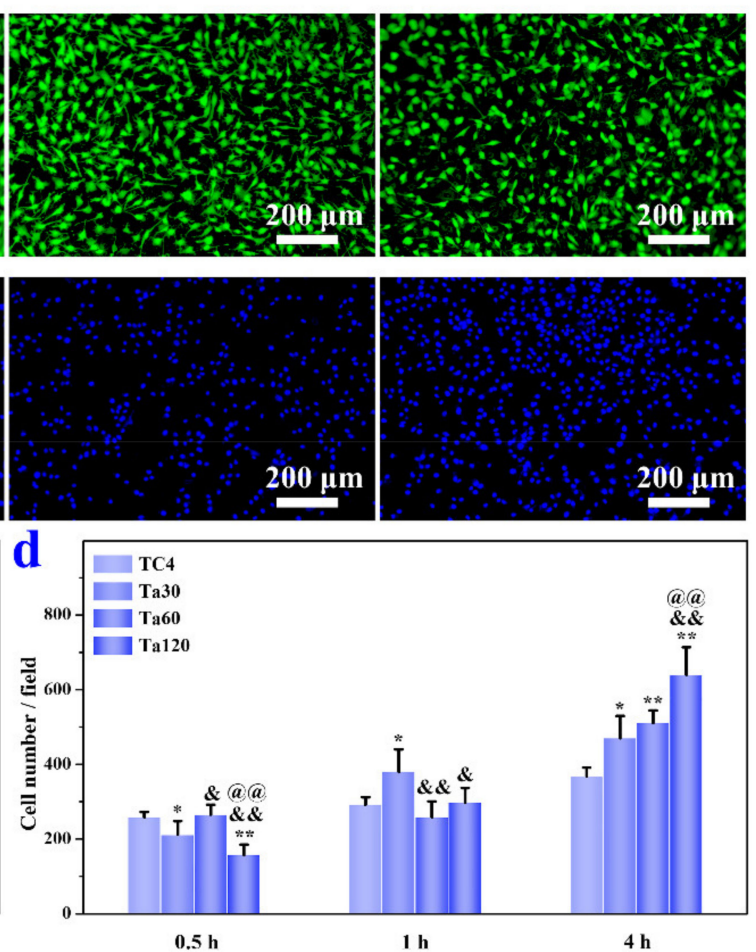

Ta120
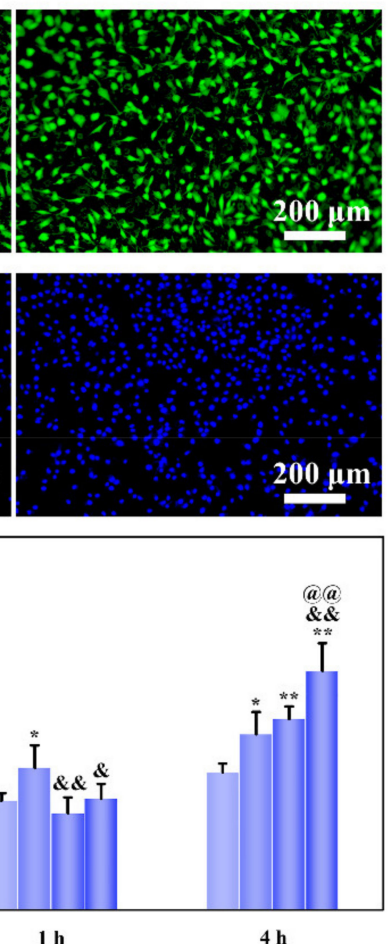

Figure 7. (a) Fluorescence images of LIVE/DEAD staining of osteoblasts cultured on Ta coatings for 3 days. (b) Fluorescence images of cells adhered on Ta coatings for $4 \mathrm{~h}$. (c) Viability of osteoblasts after culturing for 1, 3, and 5 days. (d) Quantitative results of osteoblasts adhesion after culturing for $0.5,1$ and $4 \mathrm{~h}$. Mirror polished TC 4 was used as control. ${ }^{*} p<0.05$ and ** $p<0.01$ compared to TC4, \& $p<0.05$ and \&\& $p<0.01$ compared to Ta30, ${ }^{\circledR} p<0.01$ compared to Ta60.

The morphologies of osteoblasts on Ta coatings after culturing for $24 \mathrm{~h}$ are shown in Figure 8. At low magnification (first line), cells distribute uniformly in each group. Cells on the TC4 and Ta coatings are all in a polygonal shape, but those on Ta120 seem hampered (second line). By comparing the spreading area of cells in each group, no significant difference between Ta coatings and the substrate (except Ta120) could be found. At high magnification (last line), an intimate interaction of osteoblastic pseudopodium with Ta grains can be observed on Ta coatings. A smooth surface is more favorable in upregulating focal adhesion morphology, size and, consequently, the cellular spreading area [41,42]. Compared with bare TC4, Ta coatings within the accepted surface roughness range (346.7 $\pm 66.5 \mathrm{~nm}$ of Ta60) do not compromise the cell spreading. Beyond this range, however, the spreading ability is inhibited.

The extracellular matrix mineralization levels of osteoblasts on different groups are shown in Figure 9. Ta coatings show an apparent increase in the density of mineralized nodules and darkened color after osteoinduction for 7 days and intensified after 14 days, indicating the better osteogenic activity of Ta coatings. The increased surface roughness of implants within the appropriate range can increase the surface area of implants and upregulate initial matrix deposition and earlier bone ingrowth $[43,44]$. The good extracellular matrix mineralization behavior of osteoblasts highlights the clinical potential of Ta coatings. 


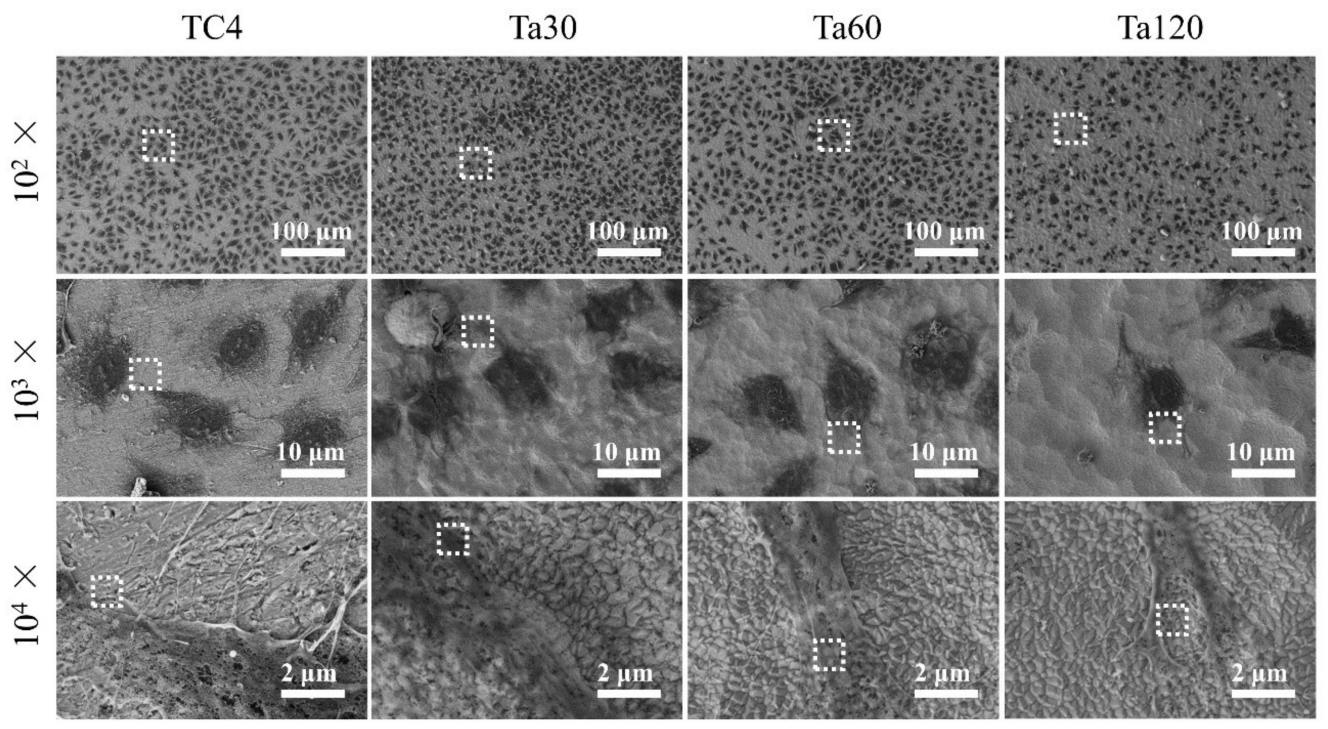

Figure 8. SEM images of osteoblasts after culturing on Ta coatings for 1 day. Mirror polished TC4 was used as control. Figures at higher magnification were taken from the area enclosed by a white square in the figures taken at lower magnification.
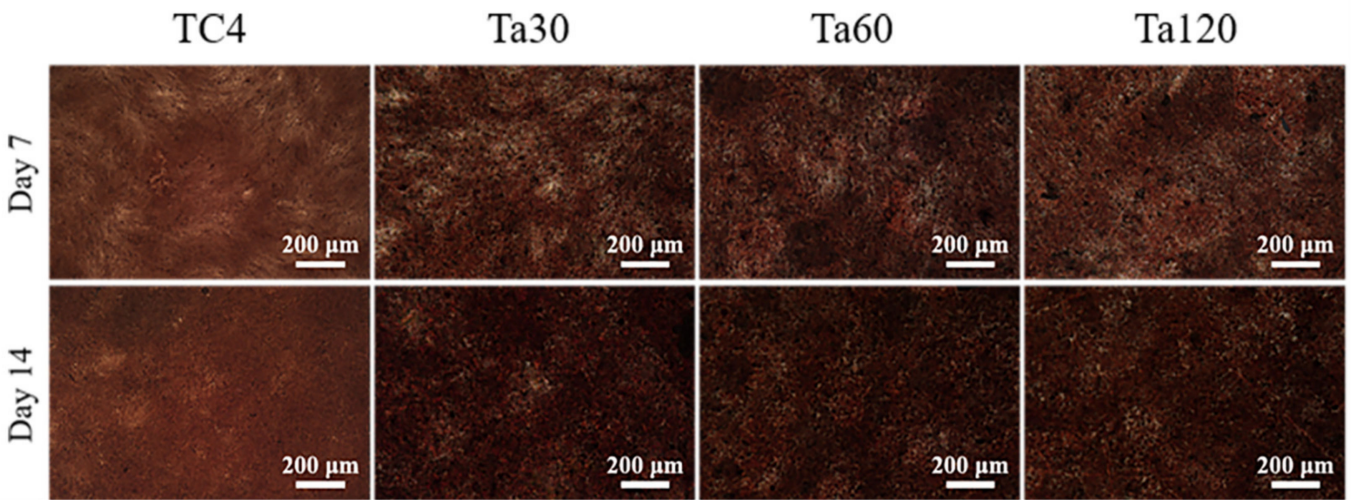

Figure 9. The extracellular matrix mineralization level of Ta coatings after osteogenic induction for 7 and 14 days. Mirror polished TC4 was used as control.

\section{Conclusions}

Gradient Ta coatings were prepared on TC4 substrate by plasma alloying technique with different alloying temperatures and time. Ta coatings prepared at $800{ }^{\circ} \mathrm{C}$ possess the optimum interfacial strength, and it increases with alloying time. At $800{ }^{\circ} \mathrm{C}$, the declined proportion of the solid solution strengthened diffusion layer with alloying time weakens the hardness and wear resistance of Ta coatings. Moreover, the corrosion resistance of Ta coatings in DMEM is significantly improved with about one order of magnitude increase in $I_{\text {corr. }}$. In vitro assays demonstrate better cytocompatibility and osteogenic activity of the Ta coating, as evidenced by the enhanced cell adhesion and extracellular matrix mineralization level of osteoblasts. The excellent interfacial strength, wear resistance, corrosion resistance, and cytocompatibility of Ta30 indicate its promising potential in dental and orthopedic applications.

Supplementary Materials: The following are available online at https://www.mdpi.com/article/ 10.3390 / coatings11060631/s1, Figure S1. The SEM images and their corresponding acoustic signal emission of samples prepared under $750{ }^{\circ} \mathrm{C}$ for $10 \mathrm{~min}(\mathrm{a} 1), 30 \mathrm{~min}(\mathrm{a} 2), 60 \mathrm{~min}(\mathrm{a} 3)$ and $120 \mathrm{~min}(\mathrm{a} 4)$; $800{ }^{\circ} \mathrm{C}$ for $10 \mathrm{~min}(\mathrm{~b} 1), 30 \mathrm{~min}(\mathrm{~b} 2), 60 \mathrm{~min}(\mathrm{~b} 3)$ and $120 \mathrm{~min}(\mathrm{~b} 4) ; 850^{\circ} \mathrm{C}$ for $10 \mathrm{~min}(\mathrm{c} 1), 30 \mathrm{~min}(\mathrm{c} 2)$, $60 \mathrm{~min}(\mathrm{c} 3)$ and $120 \mathrm{~min}(\mathrm{c} 4)$. Bar-200 $\mu \mathrm{m}$. 
Author Contributions: Conceptualization, Y.M.; Formal analysis, W.J.; Funding acquisition, H.H. and S.Y.; Investigation, Z.L.; Methodology, J.G. and Y.X.; Project administration, X.H. and Y.W.; Resources, J.G.; Software, J.B.; Supervision, S.Y.; Writing-original draft, M.Z.; Writing-review and editing, M.Z., S.Y. and Y.W. All authors have read and agreed to the published version of the manuscript.

Funding: This study was jointly supported by the National Natural Science Foundation of China (51901154, 51601124), the Natural Science Foundation of Shanxi Province (201801D221131, 201801D121094, 201901D211092), the Science and Technology Major Project of Shanxi (20181102013), and the "1331 Project" Engineering Research Center of Shanxi (PT201801). Yanpeng Xue thanks the support from Fundamental Research Funds for the Central Universities China (Project ID: FRF-TP-20-049A2).

Institutional Review Board Statement: Not applicable.

Informed Consent Statement: Not applicable.

Data Availability Statement: Data sharing not applicable.

Conflicts of Interest: The authors declare no conflict of interest.

\section{References}

1. Kaur, M.; Singh, K. Review on titanium and titanium based alloys as biomaterials for orthopaedic applications. Mat. Sci. Eng. C Mater. 2019, 102, 844-862. [CrossRef]

2. Geetha, M.; Singh, A.K.; Asokamani, R.; Gogia, A.K. Ti based biomaterials, the ultimate choice for orthopaedic implants-A review. Prog. Mater. Sci. 2009, 54, 397-425. [CrossRef]

3. Chen, Q.; Thouas, G.A. Metallic implant biomaterials. Mater. Sci. Eng. R 2015, 87, 1-57. [CrossRef]

4. Bai, L.; Liu, Y.; Zhang, X.; Huang, X.; Yao, X.; Hang, R.; Tang, B.; Xiao, Y. Favorable manipulation of macrophage/endothelial cell functionality and their cross-talk on silicon-doped titania nanotube arrays. Nanoscale 2019, 11, 5920-5931. [CrossRef] [PubMed]

5. Uddin, G.M.; Jawad, M.; Ghufran, M.; Saleem, M.W.; Raza, M.A.; Rehman, Z.U.; Arafat, S.M.; Irfan, M.; Waseem, B. Experimental investigation of tribo-mechanical and chemical properties of TiN PVD coating on titanium substrate for biomedical implants manufacturing. Int. J. Adv. Manuf. Tech. 2019, 102, 1391-1404. [CrossRef]

6. Chapala, P.; Kumar, P.S.; Joardar, J.; Bhandari, V.; Acharyya, S.G. Effect of alloying elements on the microstructure, coefficient of friction, in-vitro corrosion and antibacterial nature of selected Ti-Nb alloys. Appl. Surf. Sci. 2019, 469, 617-623. [CrossRef]

7. Xia, C.Q.; Zhang, Z.G.; Feng, Z.H.; Pan, B.; Zhang, X.Y.; Ma, M.Z.; Liu, R.P. Effect of zirconium content on the microstructure and corrosion behavior of Ti-6Al-4V-xZr alloys. Corros. Sci. 2016, 112, 687-695. [CrossRef]

8. Li, J.; He, X.; Zhang, G.; Hang, R.; Huang, X.; Tang, B.; Zhang, X. Electrochemical corrosion, wear and cell behavior of $\mathrm{ZrO}_{2} / \mathrm{TiO}_{2}$ alloyed layer on Ti-6Al-4V. Bioelectrochemistry 2018, 121, 105-114. [CrossRef]

9. Vishnu, J.; Manivasagam, G. Surface modification and biological approaches for tackling titanium wear-induced aseptic loosening. J. Bio. Tribo. Corros. 2021, 7, 1-19. [CrossRef]

10. Shi, J.; Wang, Z.; Guo, X.; Shen, J.; Sun, H.; Bai, J.; Yu, B.; Wang, L.; Zhou, W.; Liu, Y. Aspirin inhibits osteoclast formation and wear-debris-induced bone destruction by suppressing mitogen-activated protein kinases. J. Cell. Physiol. 2020, 235, 2599-2608. [CrossRef] [PubMed]

11. Meina, E.G.; Niyogi, S.; Liber, K. Investigating the mechanism of vanadium toxicity in freshwater organisms. Aquat. Toxicol. 2020, 229, 105648. [CrossRef]

12. Park, C.; Kim, S.; Kim, H.-E.; Jang, T.-S. Mechanically stable tantalum coating on a nano-roughened NiTi stent for enhanced radiopacity and biocompatibility. Surf. Coat. Tech. 2016, 305, 139-145. [CrossRef]

13. Lin, S.H.; Chien, C.S.; Kuo, T.Y.; Hsieh, Y.H.; Huang, J.W.; Chin, W.H.; Chang, C.P.; Lee, T.M.; Lee, H.T. Biomedical evaluation of vacuum plasma sprayed tantalum coatings processed by alkali treatment and alkali-heat treatment with different $\mathrm{NaOH}$ concentrations. Surf. Coat. Tech. 2020, 403, 126400. [CrossRef]

14. Ding, D.; Xie, Y.; Li, K.; Huang, L.; Zheng, X. Micro/nano structural tantalum coating for enhanced osteogenic differentiation of human bone marrow stem cells. Materials 2019, 11, 546. [CrossRef]

15. Hee, A.C.; Jamali, S.S.; Bendavid, A.; Martin, P.J.; Kong, C.; Zhao, Y. Corrosion behaviour and adhesion properties of sputtered tantalum coating on Ti6Al4V substrate. Surf. Coat. Tech. 2016, 307, 666-675. [CrossRef]

16. Wang, F.; Li, C.; Zhang, S.; Liu, H. Tantalum coated on titanium dioxide nanotubes by plasma spraying enhances cytocompatibility for dental implants. Surf. Coat. Tech. 2020, 382, 125161. [CrossRef]

17. Latif, R.; Jaafar, M.F.; Aziz, M.F.; Zain, A.R.M.; Yunas, J.; Majlis, B.Y. Influence of tantalum's crystal phase growth on the microstructural, electrical and mechanical properties of sputter-deposited tantalum thin film layer. Int. J. Refract. Met. Hard. Mater. 2020, 92, 105314. [CrossRef]

18. Wan, Y.; Tang, W.; Li, J.; Xiong, D. Comparison of method and performance in tantalum coating prepared by molten salt electroplating and glow infiltration. Surf. Coat. Tech. 2019, 375, 315-322. [CrossRef] 
19. Zhang, X.; Zhang, G.; Li, J.; He, X.; Wang, Y.; Hang, R.; Huang, X.; Tang, B.; Chu, P.K. Cellular response to nano-structured Zr and ZrO2 alloyed layers on Ti-6Al-4V. Mat. Sci. Eng. C Mater. 2018, 90, 523-530. [CrossRef]

20. Xu, J.; Sun, T.T.; Jiang, S.; Munroe, P.; Xie, Z.-H. Antimicrobial and biocorrosion-resistant $\mathrm{MoO}_{3}-\mathrm{SiO}_{2}$ nanocomposite coating prepared by double cathode glow discharge technique. Appl. Surf. Sci. 2018, 447, 500-511. [CrossRef]

21. Zhao, Y.; Xu, J.; Li, Z.; Fu, T.; Jiang, S. In vitro antibacterial properties of $\mathrm{MoO}_{3} / \mathrm{SiO}_{2} / \mathrm{Ag}_{2} \mathrm{O}$ nanocomposite coating prepared by double cathode glow discharge technique. Surf. Coat. Tech. 2020, 397, 125992. [CrossRef]

22. Xu, Z.; Liu, X.; Zhang, P.; Zhang, Y.; Zhang, G.; He, Z. Double glow plasma surface alloying and plasma nitriding. Surf. Coat. Tech. 2007, 201, 4822-4825. [CrossRef]

23. Chen, K.; Liu, X.; Liu, X.; Meng, T.; Guo, Q.; Wang, Z.; Lin, N. Microstructure and wear behavior of Ti-6Al-4V treated by plasma Zr-alloying and plasma nitriding. J. Wuhan Univ. Technol. 2016, 31, 1086-1092. [CrossRef]

24. Yuan, S.; Lin, N.; Zeng, Q.; Zhang, H.; Liu, X.; Wang, Z.; Wu, Y. Recent developments in research of double glow plasma surface alloying technology: A brief review. J. Mater. Res. Technol. 2020, 9, 6859-6882. [CrossRef]

25. Ma, Y.; Zhang, Y.; Yao, X.; Zhang, X.; Shu, X.; Tang, B. Characterization of Mo surface modified Ti by indentation techniques. Surf. Coat. Tech. 2013, 226, 75-81. [CrossRef]

26. Lin, N.; Liu, Q.; Zou, J.; Li, D.; Yuan, S.; Wang, Z.; Tang, B. Surface damage mitigation of Ti6Al4V alloy via thermal oxidation for oil and gas exploitation application: Characterization of the microstructure and evaluation of the surface performance. RSC Adv. 2017, 7, 13517-13535. [CrossRef]

27. Li, C.; Xu, Z. Diffusion Mechanism of Ion Bombardment. Surf. Eng. 2013, 3, 310-312. [CrossRef]

28. Alias, R.; Mahmoodian, R.; Genasan, K.; Vellasamy, K.M.; Shukor, M.H.A.; Kamarul, T. Mechanical, antibacterial, and biocompatibility mechanism of PVD grown silver-tantalum-oxide-based nanostructured thin film on stainless steel 316L for surgical applications. Mat. Sci. Eng. C Mater. 2020, 107, 110304. [CrossRef]

29. Jönsson, B.; Hogmark, S. Hardness measurements of thin films. Thin Solid Film. 1984, 114, 257-269. [CrossRef]

30. Ge, P.L.; Bao, M.D.; Zhang, H.J.; You, K.; Liu, X.P. Effect of plasma nitriding on adhesion strength of CrTiAlN coatings on H13 steels by closed field unbalanced magnetron sputter ion plating. Surf. Coat. Technol. 2013, 229, 146-150. [CrossRef]

31. Wang, L.; Zhong, X.; Zhao, Y.; Tao, S.; Zhang, W.; Wang, Y.; Sun, X. Design and optimization of coating structure for the thermal barrier coatings fabricated by atmospheric plasma spraying via finite element method. J. Asian Ceram. Soc. 2014, 2, 102-116. [CrossRef]

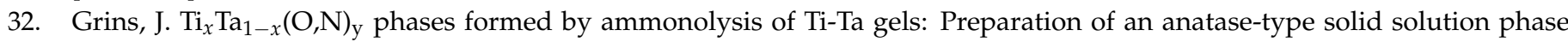
$\mathrm{Ti}_{x} \mathrm{Ta}_{1-x} \mathrm{O}_{1+x} \mathrm{~N}_{1-x}, 0.52 \leq x \leq 0.87$. J. Eur. Ceram. Soc. 1997, 17, 1819-1824. [CrossRef]

33. Wei, D.; Chen, X.; Zhang, P.; Ding, F.; Li, F.; Yao, Z. Plasma surface tantalum alloying on titanium and its corrosion behavior in sulfuric acid and hydrochloric acid. Appl. Surf. Sci. 2018, 441, 448-457. [CrossRef]

34. Zhou, X.; Huang, Y.; Chen, Y.; Peng, P. Laser joining of Mo and Ta sheets with Ti6Al4V or Ni filler. Opt. Laser Technol. 2018, 106, 487-494. [CrossRef]

35. Larosa, C.R.; Shih, M.; Varvenne, C.; Ghazisaeidi, M. Solid solution strengthening theories of high-entropy alloys. Mater. Charact. 2019, 151, 310-317. [CrossRef]

36. Bowden, D.; Krysiak, Y.; Palatinus, L.; Tsivoulas, D.; Plana-Ruiz, S.; Sarakinou, E.; Kolb, U.; Stewart, D.; Preuss, M. A high-strength silicide phase in a stainless steel alloy designed for wear-resistant applications. Nat. Commun. 2018, 9, 1-10. [CrossRef]

37. Kruzic, J.J.; Arsecularatne, J.A.; Tanaka, C.B.; Hoffman, M.J.; Cesar, P. Recent advances in understanding the fatigue and wear behavior of dental composites and ceramics. J. Mech. Behav. Biomed. Mater. 2018, 88, 504-533. [CrossRef] [PubMed]

38. Cui, W.-F.; Niu, F.-J.; Tan, Y.-L.; Qin, G.-W. Microstructure and tribocorrosion performance of nanocrystalline TiN graded coating on biomedical titanium alloy. Trans. Nonferrous Met. Soc. China 2019, 29, 1026-1035. [CrossRef]

39. Salou, L.; Hoornaert, A.; Louarn, G.; Layrolle, P. Enhanced osseointegration of titanium implants with nanostructured surfaces: An experimental study in rabbits. Acta Biomater. 2015, 11, 494-502. [CrossRef]

40. Zhang, M.; Huang, X.; Hang, R.; Zhang, X.; Tang, B. Effect of a biomimetic titania mesoporous coating doped with Sr on the osteogenic activity. Mat. Sci. Eng. C Mater. 2018, 91, 153-162. [CrossRef]

41. Zhang, M.; Wang, X.; Huang, X.; Wang, Y.; Hang, R.; Zhang, X.; Yao, X.; Tang, B. A high current anodization to fabricate a nano-porous structure on the surface of Ti-based implants. J. Mater. Sci. Mater. Med. 2018, 30, 2. [CrossRef] [PubMed]

42. Xia, J.; Yuan, Y.; Wu, H.; Huang, Y.; Weitz, D.A. Decoupling the effects of nanopore size and surface roughness on the attachment, spreading and differentiation of bone marrow-derived stem cells. Biomaterials 2020, 248, 120014. [CrossRef] [PubMed]

43. Faia-Torres, A.B.; Guimond-Lischer, S.; Rottmar, M.; Charnley, M.; Goren, T.; Maniura-Weber, K.; Spencer, N.D.; Reis, R.L.; Textor, M.; Neves, N.M. Differential regulation of osteogenic differentiation of stem cells on surface roughness gradients. Biomaterials 2014, 35, 9023-9032. [CrossRef] [PubMed]

44. Rabel, K.; Kohal, R.-J.; Steinberg, T.; Tomakidi, P.; Rolauffs, B.; Adolfsson, E.; Palmero, P.; Fürderer, T.; Altmann, B. Controlling osteoblast morphology and proliferation via surface micro-topographies of implant biomaterials. Sci. Rep. 2020, 10, 12810. [CrossRef] [PubMed] 